\title{
Impulsive End Condition for Diffusion Equation
}

\author{
By Carl E. Pearson
}

1. Introduction. Our purpose is to examine analytically and experimentally the error arising from the use of a finite difference method to solve a diffusion equation problem in which one boundary condition is impulsively changed. Specifically, we will consider the problem described by

$$
y_{t}=y_{x x}
$$

for $0 \leqq x \leqq 1$, with initial condition $y(x, 0)=0$ and end conditions $y(0, t)=1$, $y(1, t)=0$. Here $x$ is position and $t$ is time. The problem as stated is a nondimensional version of a heat-conduction problem in which a fixed temperature is suddenly applied to one end of an initially cold bar. Other diffusion problems involving impulsive boundary conditions may require a more complicated description than that given by Eq. (1); additional terms, nonconstant coefficients, or nonlinearities may well be present. Nevertheless, it may happen that even in such a case, Eq. (1) provides an adequate description of the short-time behavior of the solution, and so is suitable for a discussion of the computation error over the first few time steps. Such is the case, for example, in the viscous fluid problem which motivated the present study [1].

For the most part, we will deal with an implicit version of the finite difference approximation to Eq. (1); in many problems, such an implicit scheme is generally desirable because of computational stability with respect to large time steps or with respect to the presence of additional terms in Eq. (1). Let the interval $[0,1]$ of the $x$-axis be divided into $K$ sub-intervals, with $\delta x=1 / K$; denote the time step by $\delta t$, and the ratio $\delta t /(\delta x)^{2}$ by $A$. Then the finite difference equation to be considered is

$$
y_{j}^{n+1}=y_{j}{ }^{n}+\frac{A}{2}\left[\left(y_{j+1}^{n}+y_{j-1}^{n}-2 y_{j}{ }^{n}\right)+\left(y_{j+1}^{n+1}+y_{j-1}^{n+1}-2 y_{j}{ }^{n+1}\right)\right],
$$

where $y_{j}{ }^{n}$ denotes the computed approximation to $y(x, t)$ at $x=j \cdot \delta x$ and $t=n \cdot \delta t$.

In the problem of Eq. (1), the value of $y(0, t)$ is zero for $t \leqq 0$ and unity for $t>0$; this raises the question as to whether we should take 0 or 1 , or some in-between value, say $P$, for the value of $y_{0}{ }^{0}$ in Eq. (2). It is useful to recognize that $P$ is a parameter whose value may be chosen at will; it will turn out that, given any value of $A$, there is a choice for $P$ which minimizes the error. Thus, the initial and boundary conditions for Eq. (2) are:

$$
\begin{array}{ll}
y_{j}{ }^{0}=0 & \text { for } j=1,2, \cdots, K, \quad y_{0}{ }^{0}=P, \\
y_{0}{ }^{n}=1 & \text { for } n=1,2, \cdots, \quad y_{K}{ }^{n}=0 \quad \text { for all } n .
\end{array}
$$

One of the topics discussed in the sequel will be the results of computer experimentation with Eqs. (2) and (3) for various values of $A$ and $P$. Such solutions can be compared with the solution of Eq. (1), which for small values of time is

Received June 5, 1964. 
conveniently written*

$$
\begin{aligned}
y(x, t)=\operatorname{erfc}\left(\frac{x}{2 \sqrt{ } t}\right)-\operatorname{erfc}\left(\frac{2-x}{2 \sqrt{ } t}\right) & +\operatorname{erfc}\left(\frac{2+x}{2 \sqrt{ } t}\right) \\
& -\operatorname{erfc}\left(\frac{4-x}{2 \sqrt{ } t}\right)+\operatorname{erfc}\left(\frac{4+x}{2 \sqrt{ } t}\right)-\cdots,
\end{aligned}
$$

where

$$
\operatorname{erfc}(\beta)=\frac{2}{\sqrt{ } \pi} \int_{\beta}^{\infty} e^{-\xi^{2}} d \xi
$$

The computer solutions show that there can be substantial errors (and also oscillations) resulting from the use of Eq. (2). As $n$ increases, these errors tend to become small; this effect has been observed by Albasiny [2] in a similar problem. We also describe the results of some computer solutions of Eq. (2) in which the first time step is, however, now made exact by use of Eq. (4). This turns out to result in a high degree of accuracy for future time steps; the efficacy of such a procedure has been previously suggested in reference [3]. Results obtained by the use of an explicit difference equation as a replacement for Eq. (2) are also mentioned.

In Section 3, we obtain some closed-form expressions for the solution of Eq. (2). These expressions are used to discuss analytically the behavior of the solution for small values of $n$ and $j$; we also use them to show that, as $n$ becomes large, the solution of Eq. (2) can be expected to approach asymptotically that of Eq. (1) (for any choice of $A$ and $P$ ). We will simplify the derivation of these analytical results by setting $K=\infty$ in Eq. (3). That this is legitimate follows from the observation that the discrepancy between the computed solution of Eqs. (2) and (3), and that given by Eq. (4), is usually important only for small values of $t$; for these small $t$-values, the effect of the end-condition at $x=1$ (which is responsible for the presence of all terms beyond the first in Eq. (4)) is not felt. Thus, the closed-form solutions of Eq. (2) will be obtained for the initial and boundary conditions

$$
\begin{aligned}
& y_{j}{ }^{0}=0 \text { for } j=1,2,3, \cdots, \quad y_{0}{ }^{0}=P, \\
& y_{0}{ }^{n}=1 \text { for } n=1,2,3, \cdots, \quad y_{j}{ }^{n} \rightarrow 0 \text { as } j \rightarrow \infty \text {. }
\end{aligned}
$$

2. Numerical Results. Choosing $K=100$, computer solutions of Eqs. (2) and (3) were obtained for all possible combinations of values of $A=10,2.5,1, .25$, and $P=1, .5, .25, .1,0$, and these computer results were compared with the exact solution as obtained by use of Eq. (4). Comparative tables of results were prepared; one representative table-for the case $A=2.5, P=1$-is included as Table 1 of the present paper. The first line of each double row is the computed solution, and the second line is the exact solution, at the mesh points $x=j \cdot \delta x, t=n \cdot \delta t$. Lack of space precluded the inclusion of the remaining tables, but copies are available from the author on request.

Examination of these tables shows that in all cases the error decays as $n$ in-

* This form of the solution may be obtained by taking a Laplace transform in time of Eq. (1), expanding the transform function in powers of $\exp (-s)$, and integrating the inversion formula term by term. 
TABLE 1

$A=2.500 \quad P=1.000$

\begin{tabular}{|c|c|c|c|c|c|c|c|c|c|}
\hline & $J=1$ & $J=2$ & $J=3$ & $J=4$ & $J=5$ & $J=6$ & $J=7$ & $J=8$ & $J=9$ \\
\hline$N=1$ & $\begin{array}{l}0.8404 \\
0.6547\end{array}$ & $\begin{array}{l}0.3531 \\
0.3711\end{array}$ & $\begin{array}{l}0.1484 \\
0.1797\end{array}$ & $\begin{array}{l}0.0624 \\
0.0736\end{array}$ & $\begin{array}{l}0.0262 \\
0.0253\end{array}$ & $\begin{array}{l}0.0110 \\
0.0073\end{array}$ & $\begin{array}{l}0.0046 \\
0.0017\end{array}$ & $\begin{array}{l}0.0019 \\
0.0003\end{array}$ & $\begin{array}{l}0.0008 \\
0.0001\end{array}$ \\
\hline$N=2$ & $\begin{array}{l}0.6862 \\
0.7518\end{array}$ & $\begin{array}{l}0.5767 \\
0.5271\end{array}$ & $\begin{array}{l}0.3635 \\
0.3428\end{array}$ & $\begin{array}{l}0.2037 \\
0.2059\end{array}$ & $\begin{array}{l}0.1070 \\
0.1138\end{array}$ & $\begin{array}{l}0.0539 \\
0.0578\end{array}$ & $\begin{array}{l}0.0264 \\
0.0269\end{array}$ & $\begin{array}{l}0.0127 \\
0.0114\end{array}$ & $\begin{array}{l}0.0060 \\
0.0044\end{array}$ \\
\hline$N=3$ & $\begin{array}{l}0.8346 \\
0.7963\end{array}$ & $\begin{array}{l}0.5837 \\
0.6056\end{array}$ & $\begin{array}{l}0.4421 \\
0.4386\end{array}$ & $\begin{array}{l}0.3101 \\
0.3017\end{array}$ & $\begin{array}{l}0.2000 \\
0.1967\end{array}$ & $\begin{array}{l}0.1207 \\
0.1213\end{array}$ & $\begin{array}{l}0.0692 \\
0.0707\end{array}$ & $\begin{array}{l}0.0381 \\
0.0389\end{array}$ & $\begin{array}{l}0.0204 \\
0.0201\end{array}$ \\
\hline$N=4$ & $\begin{array}{l}0.8054 \\
0.8231\end{array}$ & $\begin{array}{l}0.6729 \\
0.6547\end{array}$ & $\begin{array}{l}0.5024 \\
0.5023\end{array}$ & $\begin{array}{l}0.3706 \\
0.3711\end{array}$ & $\begin{array}{l}0.2652 \\
0.2636\end{array}$ & $\begin{array}{l}0.1813 \\
0.1797\end{array}$ & $\begin{array}{l}0.1181 \\
0.1175\end{array}$ & $\begin{array}{l}0.0736 \\
0.0736\end{array}$ & $\begin{array}{l}0.0441 \\
0.0442\end{array}$ \\
\hline$N=5$ & $\begin{array}{l}0.8525 \\
0.8415\end{array}$ & $\begin{array}{l}0.6805 \\
0.6892\end{array}$ & $\begin{array}{l}0.5526 \\
0.5485\end{array}$ & $\begin{array}{l}0.4263 \\
0.4237\end{array}$ & $\begin{array}{l}0.3181 \\
0.3173\end{array}$ & $\begin{array}{l}0.2307 \\
0.2301\end{array}$ & $\begin{array}{l}0.1621 \\
0.1615\end{array}$ & $\begin{array}{l}0.1101 \\
0.1096\end{array}$ & $\begin{array}{l}0.0721 \\
0.0719\end{array}$ \\
\hline$N=6$ & $\begin{array}{l}0.8497 \\
0.8551\end{array}$ & $\begin{array}{l}0.7217 \\
0.7150\end{array}$ & $\begin{array}{l}0.5826 \\
0.5839\end{array}$ & $\begin{array}{l}0.4658 \\
0.4652\end{array}$ & $\begin{array}{l}0.3626 \\
0.3613\end{array}$ & $\begin{array}{l}0.2742 \\
0.2733\end{array}$ & $\begin{array}{l}0.2018 \\
0.2012\end{array}$ & $\begin{array}{l}0.1445 \\
0.1441\end{array}$ & $\begin{array}{l}0.1007 \\
0.1003\end{array}$ \\
\hline$N=7$ & $\begin{array}{l}0.8693 \\
0.8658\end{array}$ & $\begin{array}{l}0.7321 \\
0.7353\end{array}$ & $\begin{array}{l}0.6144 \\
0.6121\end{array}$ & $\begin{array}{l}0.4996 \\
0.4990\end{array}$ & $\begin{array}{l}0.3984 \\
0.3980\end{array}$ & $\begin{array}{l}0.3111 \\
0.3105\end{array}$ & $\begin{array}{l}0.2373 \\
0.2367\end{array}$ & $\begin{array}{l}0.1767 \\
0.1763\end{array}$ & $\begin{array}{l}0.1286 \\
0.1282\end{array}$ \\
\hline$N=8$ & $\begin{array}{l}0.8726 \\
0.8744\end{array}$ & $\begin{array}{l}0.7544 \\
0.7518\end{array}$ & $\begin{array}{l}0.6345 \\
0.6353\end{array}$ & $\begin{array}{l}0.5277 \\
0.5271\end{array}$ & $\begin{array}{l}0.4298 \\
0.4292\end{array}$ & $\begin{array}{l}0.3432 \\
0.3428\end{array}$ & $\begin{array}{l}0.2688 \\
0.2684\end{array}$ & $\begin{array}{l}0.2063 \\
0.2059\end{array}$ & $\begin{array}{l}0.1551 \\
0.1547\end{array}$ \\
\hline$N=9$ & $\begin{array}{l}0.8827 \\
0.8815\end{array}$ & $\begin{array}{l}0.7644 \\
0.7656\end{array}$ & $\begin{array}{l}0.6558 \\
0.6547\end{array}$ & $\begin{array}{l}0.5512 \\
0.5510\end{array}$ & $\begin{array}{l}0.4564 \\
0.4561\end{array}$ & $\begin{array}{l}0.3715 \\
0.3711\end{array}$ & $\begin{array}{l}0.2971 \\
0.2967\end{array}$ & $\begin{array}{l}0.2334 \\
0.2330\end{array}$ & $\begin{array}{l}0.1800 \\
0.1797\end{array}$ \\
\hline$N=10$ & $\begin{array}{l}0.8869 \\
0.8875\end{array}$ & $\begin{array}{l}0.7783 \\
0.7773\end{array}$ & $\begin{array}{l}0.6710 \\
0.6714\end{array}$ & $\begin{array}{l}0.5720 \\
0.5716\end{array}$ & $\begin{array}{l}0.4798 \\
0.4795\end{array}$ & $\begin{array}{l}0.3964 \\
0.3961\end{array}$ & $\begin{array}{l}0.3225 \\
0.3222\end{array}$ & $\begin{array}{l}0.2582 \\
0.2579\end{array}$ & $\begin{array}{l}0.2034 \\
0.2031\end{array}$ \\
\hline
\end{tabular}

creases; moreover, for any choice of $A$, the error can be minimized by choosing an optimal value for $P$ (a formula for this optimal value will be obtained in Section 3 ). The fact that the solution becomes accurate after a certain number of time steps has the practical implication that, if a time step $\delta t$ is to be used through a given problem involving the kind of impulsive boundary condition here considered, then it may be useful to make a special calculation for the first time step. This special calculation would consist in dividing the first time step $\delta t$ into a number $M$ of sub-intervals, with $\delta t^{\prime}=\delta t / M$, and applying Eq. (2) to each such sub-intervâl; the appropriate values of $M$ and $P$ can be estimated from the above-mentioned tables (where $A$ would be calculated from $\delta t^{\prime}$ rather than from $\delta t$, of course).

Computer results were also obtained for $A=10,2.5,1$, for the case in which the first time step is made exact by use of Eq. (4). Table 2 is typical of the results obtained. It is clear that this is a very effective procedure; although it may not always be practical to use Eq. (4) - or its equivalent in more complicated situations-the procedure described in the preceding paragraph may be feasible, and we can then deduce that accuracy in the first time step will lead to accuracy for successive time steps. Results were also obtained for the explicit formula

$$
y_{j}{ }^{n+1}=y_{j}{ }^{n}+A\left[y_{j+1}^{n}+y_{j-1}^{n}-2 y_{j}{ }^{n}\right]
$$

as a replacement for Eq. (2); for comparable values of $A$, errors resulting from the impulsive end condition were comparable to those obtained by use of Eq. (2). (Equation (6) is, of course, neither as stable nor as accurate as Eq. (2).) 
TABLE 2

\begin{tabular}{|c|c|c|c|c|c|c|c|c|c|}
\hline & $J=1$ & $J=2$ & $J=3$ & $J=4$ & $J=5$ & $J=6$ & $J=7$ & $J=8$ & $J=9$ \\
\hline$N=1$ & $\begin{array}{l}0.6547 \\
0.6547\end{array}$ & $\begin{array}{l}0.3711 \\
0.3711\end{array}$ & $\begin{array}{l}0.1797 \\
0.1797\end{array}$ & $\begin{array}{l}0.0736 \\
0.0736\end{array}$ & $\begin{array}{l}0.0253 \\
0.0253\end{array}$ & $\begin{array}{l}0.0073 \\
0.0073\end{array}$ & $\begin{array}{l}0.0017 \\
0.0017\end{array}$ & $\begin{array}{l}0.0003 \\
0.0003\end{array}$ & $\begin{array}{l}0.0001 \\
0.0001\end{array}$ \\
\hline$N=2$ & $\begin{array}{l}0.7563 \\
0.7518\end{array}$ & $\begin{array}{l}0.5323 \\
0.5271\end{array}$ & $\begin{array}{l}0.3449 \\
0.3428\end{array}$ & $\begin{array}{l}0.2044 \\
0.2059\end{array}$ & $\begin{array}{l}0.1108 \\
0.1138\end{array}$ & $\begin{array}{l}0.0554 \\
0.0578\end{array}$ & $\begin{array}{l}0.0259 \\
0.0269\end{array}$ & $\begin{array}{l}0.0115 \\
0.0114\end{array}$ & $\begin{array}{l}0.0050 \\
0.0044\end{array}$ \\
\hline$N=3$ & $\begin{array}{l}0.7970 \\
0.7963\end{array}$ & $\begin{array}{l}0.6070 \\
0.6056\end{array}$ & $\begin{array}{l}0.4400 \\
0.4386\end{array}$ & $\begin{array}{l}0.3023 \\
0.3017\end{array}$ & $\begin{array}{l}0.1960 \\
0.1967\end{array}$ & $\begin{array}{l}0.1198 \\
0.1213\end{array}$ & $\begin{array}{l}0.0691 \\
0.0707\end{array}$ & $\begin{array}{l}0.0378 \\
0.0389\end{array}$ & $\begin{array}{l}0.0198 \\
0.0201\end{array}$ \\
\hline$N=4$ & $\begin{array}{l}0.8235 \\
0.8231\end{array}$ & $\begin{array}{l}0.6554 \\
0.6547\end{array}$ & $\begin{array}{l}0.5028 \\
0.5023\end{array}$ & $\begin{array}{l}0.3712 \\
0.3711\end{array}$ & $\begin{array}{l}0.2632 \\
0.2636\end{array}$ & $\begin{array}{l}0.1790 \\
0.1797\end{array}$ & $\begin{array}{l}0.1166 \\
0.1175\end{array}$ & $\begin{array}{l}0.0727 \\
0.0736\end{array}$ & $\begin{array}{l}0.0435 \\
0.0442\end{array}$ \\
\hline$N=5$ & $\begin{array}{l}0.8416 \\
0.8415\end{array}$ & $\begin{array}{l}0.6893 \\
0.6892\end{array}$ & $\begin{array}{l}0.5486 \\
0.5485\end{array}$ & $\begin{array}{l}0.4236 \\
0.4237\end{array}$ & $\begin{array}{l}0.3170 \\
0.3173\end{array}$ & $\begin{array}{l}0.2296 \\
0.2301\end{array}$ & $\begin{array}{l}0.1608 \\
0.1615\end{array}$ & $\begin{array}{l}0.1089 \\
0.1096\end{array}$ & $\begin{array}{l}0.0713 \\
0.0719\end{array}$ \\
\hline$N=6$ & $\begin{array}{l}0.8551 \\
0.8551\end{array}$ & $\begin{array}{l}0.7150 \\
0.7150\end{array}$ & $\begin{array}{l}0.5838 \\
0.5839\end{array}$ & $\begin{array}{l}0.4650 \\
0.4652\end{array}$ & $\begin{array}{l}0.3610 \\
0.3613\end{array}$ & $\begin{array}{l}0.2728 \\
0.2733\end{array}$ & $\begin{array}{l}0.2007 \\
0.2012\end{array}$ & $\begin{array}{l}0.1436 \\
0.1441\end{array}$ & $\begin{array}{l}0.0998 \\
0.1003\end{array}$ \\
\hline$N=7$ & $\begin{array}{l}0.8657 \\
0.8658\end{array}$ & $\begin{array}{l}0.7352 \\
0.7353\end{array}$ & $\begin{array}{l}0.6119 \\
0.6121\end{array}$ & $\begin{array}{l}0.4987 \\
0.4990\end{array}$ & $\begin{array}{l}0.3976 \\
0.3980\end{array}$ & $\begin{array}{l}0.3100 \\
0.3105\end{array}$ & $\begin{array}{l}0.2362 \\
0.2367\end{array}$ & $\begin{array}{l}0.1758 \\
0.1763\end{array}$ & $\begin{array}{l}0.1277 \\
0.1282\end{array}$ \\
\hline$N=8$ & $\begin{array}{l}0.8743 \\
0.8744\end{array}$ & $\begin{array}{l}0.7517 \\
0.7518\end{array}$ & $\begin{array}{l}0.6350 \\
0.6353\end{array}$ & $\begin{array}{l}0.5268 \\
0.5271\end{array}$ & $\begin{array}{l}0.4288 \\
0.4292\end{array}$ & $\begin{array}{l}0.3423 \\
0.3428\end{array}$ & $\begin{array}{l}0.2679 \\
0.2684\end{array}$ & $\begin{array}{l}0.2054 \\
0.2059\end{array}$ & $\begin{array}{l}0.1543 \\
0.1547\end{array}$ \\
\hline$N=9$ & $\begin{array}{l}0.8814 \\
0.8815\end{array}$ & $\begin{array}{l}0.7654 \\
0.7656\end{array}$ & $\begin{array}{l}0.6545 \\
0.6547\end{array}$ & $\begin{array}{l}0.5506 \\
0.5510\end{array}$ & $\begin{array}{l}0.4556 \\
0.4561\end{array}$ & $\begin{array}{l}0.3706 \\
0.3711\end{array}$ & $\begin{array}{l}0.2962 \\
0.2967\end{array}$ & $\begin{array}{l}0.2326 \\
0.2330\end{array}$ & $\begin{array}{l}0.1793 \\
0.1797\end{array}$ \\
\hline$N=10$ & $\begin{array}{l}0.8874 \\
0.8875\end{array}$ & $\begin{array}{l}0.7771 \\
0.7773\end{array}$ & $\begin{array}{l}0.6711 \\
0.6714\end{array}$ & $\begin{array}{l}0.5713 \\
0.5716\end{array}$ & $\begin{array}{l}0.4791 \\
0.4795\end{array}$ & $\begin{array}{l}0.3957 \\
0.3961\end{array}$ & $\begin{array}{l}0.3217 \\
0.3222\end{array}$ & $\begin{array}{l}0.2575 \\
0.2579\end{array}$ & $\begin{array}{l}0.2027 \\
0.2031\end{array}$ \\
\hline
\end{tabular}

3. Closed-form Solutions. We will now derive some analytical solutions of Eqs. (2) and (5). We begin by writing a version of the Fourier sine transform formula $\dagger$ applicable to a mesh-point function $w(j)$ defined for $j=1,2,3, \cdots$ :

$$
w(j)=\frac{2}{\pi} \int_{0}^{\infty} \sin \lambda j \frac{\sin (\lambda / 2)}{(\lambda / 2)} d \lambda \sum_{k=1}^{\infty} w(k) \sin \lambda k .
$$

To solve Eqs. (2) and (5), we define a transform function $Y(n, \lambda)$ by

$$
Y(n, \lambda)=\sum_{j=1}^{\infty} y_{j}^{n} \sin \lambda j
$$

for $n=0,1,2, \cdots$. Multiplying each side of Eq. (2) by $\sin \lambda j$, and summing over $j$ from 1 to $\infty$, we obtain a difference equation for $Y(n, \lambda)$ which-by use of the initial conditions described in Eq. (5) - is easily solved to give

where

$$
Y(n, \lambda)=\frac{\sin \lambda}{4 \sin ^{2}(\lambda / 2)}[1-Q(n, \lambda)]
$$

$$
Q(n, \lambda)=\frac{1-2 A P \sin ^{2}(\lambda / 2)}{1+2 A \sin ^{2}(\lambda / 2)}\left(\frac{1-2 A \sin ^{2}(\lambda / 2)}{1+2 A \sin ^{2}(\lambda / 2)}\right)^{n-1} .
$$

$\dagger$ To derive this formula, define a function $f(x)$ such that $f(x)=w(j)$ for $x$ in $\left(j-\frac{1}{2}\right.$, $\left.j+\frac{1}{2}\right), j=1,2,3, \cdots$, and $f(x)=0$ for $x$ in $\left(0, \frac{1}{2}\right)$; then apply the usual sine transform formula $f(x)=2 / \pi \int_{0}^{\infty} \sin \lambda x \cdot d \lambda \int_{0}^{\infty} \sin \lambda \xi \cdot f(\xi) \cdot d \xi$. We assume that the behavior of $w(j)$ for large $j$ is such that this formula is valid for the corresponding function $f(x)$. 
Equation (8) is valid for $n=1,2,3, \cdots$. From Eq. (7), we now obtain

$$
y_{j}^{n}=1-\frac{1}{\pi} \int_{-\infty}^{\infty} \frac{\sin 2 \lambda j}{\lambda} \cdot \cos \lambda \cdot Q(n, 2 \lambda) d \lambda
$$

for $j=1,2,3, \cdots, n=1,2,3, \cdots$. We have taken advantage of the evenness of the integrand to change the range of integration to the interval $(-\infty, \infty)$. Using now

$$
\int_{-\infty}^{\infty}=\cdots+\int_{-3 \pi}^{-\pi}+\int_{-\pi}^{\pi}+\int_{\pi}^{3 \pi}+\cdots
$$

and also the expansion

we obtain

$$
\frac{1}{2} \cot \frac{\lambda}{2}=\frac{1}{\lambda}+\frac{2 \lambda}{\lambda^{2}-(2 \pi)^{2}}+\frac{2 \lambda}{\lambda^{2}-(4 \pi)^{2}}
$$

$$
y_{j}^{n}=1-\frac{1}{2 \pi} \int_{-\pi}^{\pi} \sin 2 \lambda j \cdot \cos \lambda \cdot \cot (\lambda / 2) \cdot Q(n, 2 \lambda) d \lambda .
$$

The usual $e^{i \lambda}=z$ transformation would give a contour integral around the unit circle, and residues could be summed to give algebraic formulas for $y_{j}{ }^{n}$ for various choices of $n, j$; however, Eq. (11) will be more useful for this purpose. We will here use Eq. (9) to show that, for any choice of $A$ and $P$, the solution becomes asymptotic to the first term of Eq. (4) as $n$ becomes large. We observe that, for large $n, Q(n, 2 \lambda)$ is small except near $\lambda=0, \pm \pi$; however, the regions near $\pm \pi$ may be discarded because of the vanishing there of the rest of the integrand. Thus, for large $n$, only the neighborhood of the origin is important, and a conventional asymptotic calculation gives

$$
y_{j}{ }^{n} \sim 1-\frac{j \cdot \delta x}{\sqrt{ }(\pi n \cdot \delta t)} .
$$

This result is equivalent to the behavior of $\operatorname{erfc}(x / 2 \sqrt{ } t)$ for large $t$;

$$
\operatorname{erfc}\left(\frac{x}{2 \sqrt{ } t}\right) \sim 1-\frac{x}{\sqrt{ }(\pi t)}
$$

so we conclude that the numerical solution given by Eq. (2) will normally become asymptotically correct, as $n$ grows.

To investigate the initial errors in the vicinity of $x=0$, it is convenient to obtain a different form of Eq. (9). We introduce the generating function

$$
Y(z, j)=\sum_{n=0}^{\infty} y_{j}{ }^{n} z^{n}
$$

where this power series in the complex variable $z$ is assumed to converge. Multiplication of both sides of Eq. (2) by $z^{n}$ and summation over $n$ from 0 to $\infty$ gives a difference equation for $Y(z, j)$; using the initial and end conditions $(5)$, the solution of this difference equation is readily seen to be

$$
\begin{aligned}
& Y(z, j)=\left(\frac{z}{1-z}+\frac{P z}{1+z}\right) \\
& \cdot\left[1+\frac{1}{A}\left(\frac{1-z}{1+z}\right)-\sqrt{ }\left(\frac{2}{A}\left(\frac{1-z}{1+z}\right)+\frac{1}{A^{2}}\left(\frac{1-z}{1+z}\right)^{2}\right)\right]^{j} .
\end{aligned}
$$


From Eq. (9), we see that $y_{j}{ }^{n}$ is the coefficient of $z^{n}$ in the expansion around the origin of $Y(z, j)$; this leads to the results:

$$
\begin{aligned}
y_{1}{ }^{=}= & (1+P)\left\{1+\frac{1}{A}-\frac{1}{A} \sqrt{ }(1+2 A)\right\}, \\
y_{1}{ }^{2}= & \left\{1-\frac{1}{A}+\frac{1}{A \sqrt{ }(1+2 A)}\right\}+P\left\{-1-\frac{3}{A}+\frac{1}{A} \frac{4 A+3}{\sqrt{ }(1+2 A)}\right\} . \\
y_{1}{ }^{2}= & \left\{1+\frac{1}{A}-\frac{\sqrt{ }(1+2 A)}{2 A}\left[\frac{2 A+3}{2 A+1}-\frac{1}{(2 A+1)^{2}}\right]\right\} \\
& +P\left\{1+\frac{3}{A}+\frac{2}{A^{2}}-\frac{2}{A} \frac{A^{2}+3 A+1}{\sqrt{ }(1+2 A)^{3}}-\frac{1}{A} \frac{4 A+3}{\sqrt{ }(1+2 A)}\right\}, \\
y_{2}{ }^{1}= & (1+P)\left\{1+\frac{1}{A}-\frac{1}{A} \sqrt{ }(1+2 A)\right\}^{2}, \\
y_{3}{ }^{1}= & (1+P)\left\{1+\frac{1}{A}-\frac{1}{A} \sqrt{ }(1+2 A)\right\}^{3},
\end{aligned}
$$

For comparison, the exact solution, as obtained from the first term of Eq. (4), is

$$
\left(y_{j}{ }^{n}\right) \text { exact }=\operatorname{erfc}\left(\frac{j}{2 \sqrt{ }(n A)}\right) .
$$

It is clear that, for certain choices of $A$ and $P$, the error can be very large over the first few time steps. In Section 2 we observed that it was desirable to make the error for the first time step, $n=1$, as small as possible; this suggests that a criterion for choosing $P$ can be obtained by minimizing the sum of squared errors for $n=1$. Setting the derivative with respect to $P$ of this squared error sum

$$
\sum_{j=1}^{\infty}\left\{\operatorname{erfc}\left(\frac{j}{2 \sqrt{ } A}\right)-(1+P)\left[1+\frac{1}{A}-\frac{1}{A} \sqrt{ }(1+2 A)\right]^{j}\right\}^{2}
$$

equal to zero, we obtain the criterion

$$
P=\frac{\sum_{j=1}^{\infty}\left\{\operatorname{erfc}\left(\frac{j}{2 \sqrt{ } A}\right)-\left[1+\frac{1}{A}-\frac{1}{A} \sqrt{ }(1+2 A)\right]^{j}\right\}}{\cdot\left\{1+\frac{1}{A}-\frac{1}{A} \sqrt{ }(1+2 A)\right\}^{j}} .
$$

The terms in Eq. (12) usually decrease rapidly with $j$, so that the formula is easy to use. For $A=1$, for example, it gives

$$
P=\frac{.057+.006+.001+\cdots}{.072+.005+\cdots}=.83
$$

(and from the tables of solutions it is seen that this is a reasonable result). Equation (12) also indicates that as $A$ becomes large, $P$ should be made small.

Either from an examination of tables of computer solutions, or by use of Eq. (11), we see that the solution of Eq. (2) can be oscillatory for certain choices of $A$ 
and $P$; we remark that this feature is not exhibited by solutions of the explicit Eq. (6), since it is easy to show that $y_{j}{ }^{n+1}-y_{j}{ }^{n}$ is always $>0$, for any choice of $A$ satisfying the stability condition $A<\frac{1}{2}$.

Sperry Rand Research Laboratory

Sudbury, Massachusetts

1. C. E. Pearson, "Numerical solutions for the time-dependent viscous flow between two rotating coaxial disks," J. Fluid Mech., v. 21, 1965, pp. $623-633$.

2. E. L. Albasiny, "On a cylindrical heat-conduction problem," Quart. J. Mech. Appl. Math., v. 13, 1960, pp. 374-384. MR 22 * 6087.

3. Modern Computing Methods, Notes on Applied Science, No. 16, National Physical Laboratory, Her Majesty's Stationery Office, London, 1957. 